\title{
Do Patients With Osteoarthritis get Weight Loss Counseling?
}

Syed Hashim Ali Inam ${ }^{1}$, Bismah Riaz ${ }^{2}$, Hamza Jamil ${ }^{1}$, Daneyal Rafique ${ }^{1}$, Umair Asif Siddiqi ${ }^{1}$, Mishal Iqbal $^{3}$, Nawabzada Zeerak Farhat Sherwani ${ }^{2}$, Waqas Khan ${ }^{1}$

1. Internal Medicine, Army Medical College, National University of Medical Sciences (NUMS), Rawalpindi, PAK 2. Internal Medicine, CMH Lahore Medical and Dental College, Lahore, PAK 3. Internal Medicine, Military Hospital, Rawalpindi, PAK

Corresponding author: Bismah Riaz, basmah_riaz@hotmail.co.uk

\begin{abstract}
Introduction: Osteoarthritis $(\mathrm{OA})$ is a degenerative disease of joints which if untreated can lead to a permanent disability of joints. Obesity plays an important role in the morbidity of OA. Since there is no curative treatment for $\mathrm{OA}$, several researches focusing on nonpharmacological intervention for OA have come forth. Triad of education, exercise, and weight loss has been gaining popularity as a first-line nonpharmacological treatment for OA. This article measures the number of OA patients, irrespective of age and gender, who have received weight-loss counseling from their physicians and it also studies patients willingness to lose weight after being counseled.
\end{abstract}

Methodology: A cross-sectional study was conducted from 10th June 2020 to 10th July 2020. Diagnosed cases of OA were included and their consent was taken. A self-administered questionnaire was used which included questions asking if they have ever received weight-loss counseling and if they will try to lose weight on being advised by their physician. Data were collected from the participants using google forms and analyzed using SPSS-22.

Results: Out of 199 OA patients included in our study, only 28 (14\%) participants received weight loss and exercise counseling from their physicians. A positive response was observed in 175 (87.9\%) participants out of 199 who reported that they would exercise and practice a healthy lifestyle to lose weight if they were advised properly.

Conclusion: Results of our study showed that the total number of OA patients receiving advice from their treating physician regarding weight loss is less. However, the majority of the patients were willing to exercise and control their weight if advised properly by their physician.

Review began 09/14/2020 Review ended 11/05/2020 Published 11/16/2020

(c) Copyright 2020 Inam et al. This is an open access article distributed under the terms of the Creative Commons Attribution License CC-BY 4.0., which permits unrestricted use, distribution, and reproduction in any medium, provided the original author and source are credited.
Categories: Internal Medicine, Medical Education, Orthopedics

Keywords: arthritis, weight loss counselling, exercise, physician counselling, osteoarthritis

\section{Introduction}

Osteoarthritis (OA) is a degenerative joint disorder [1]. It is diagnosed clinically, and radiological evidence supports the diagnosis [2]. According to the World Health Organization (WHO), OA will become the fourth leading cause of disability by the end of the year 2020 [2].

Obesity and being overweight has a strong relation with OA's progression and its prevalence [3]. In 20152016 , the prevalence of obesity was $39.8 \%$ in adults [4]. The prevalence of obesity is increasing day by day with almost one-third of the world's population included in the overweight or obese category [5]. According to an estimate, approximately $60 \%$ of the world population will be overweight by 2030 if the current trends continue [6].

A directly proportional relation is established between weight loss and symptomatic improvement of OA [7]. Losing weight is considered to be a research-proven first-line therapy for $\mathrm{OA}$ [8]. Because of this relationship between weight loss and OA morbidity improvement, the role of exercise and weight loss counseling by the physician is of paramount importance [9]. All international practice guidelines such as Osteoarthritis Research Society International (OARSI) guidelines and the National Institute for Health and Care Excellence (NICE) guidelines recommend that patients with OA should be counseled to lose weight [10-11]. Proper weight loss counseling from the physicians in OA patients is known to improve patient compliance and health outcomes [12].

Due to the scarcity of literature on the relationship between OA prognosis and weight-loss counseling, there was limited data to compare our results with. However, our article will add to the literature on this topic. In light of these facts, our study aims to discover the actual number of patients receiving weight-loss advice from their physicians as a part of the treatment of OA. 


\section{Cureus}

\section{Materials And Methods}

A cross-sectional study was conducted at a tertiary care hospital in Rawalpindi, Pakistan from 10th June 2020 to 10th July 2020. Patients diagnosed with OA who gave consent to participate in the research were included in the study. A self-designed questionnaire was used. Data were collected using google forms after the consent was taken. The confidentiality of the data was maintained. The data were analyzed using SPSS22. A convenient sampling technique was used and 199 OA patients agreed to participate in the study in this period. The first portion of the questionnaire consisted of patient's demographics and the second portion had questions asking about the duration of arthritis, counseling received or not, willingness to lose weight after the advice of the doctor, and source of counseling.

\section{Results}

Our study included a total of 199 participants, out of which 130 (65.3\%) were females and 69 (34.7\%) were males. On inquiring about the education of patients, 87 (43.7\%) had studied till high-school, 35 (17.6\%) had completed their bachelor's degree, and 27 (13.6\%) had done their master's. Around 50 (25.1\%) participants had never been to school and were included in the category of uneducated. A total of 70 (35.2\%) participants were diagnosed with OA more than five years ago and $32(16.1 \%)$ had OA for only a year. The duration of the rest of the patients was between one and five years. The mean duration of OA diagnosis was 2.44 years with a standard deviation of 1.011. Among participants, only 28 (14\%) out of 199 had received weight-loss counseling from doctors or health care professionals, and 171 (86\%) reported that they had not received any advice regarding weight loss from doctors. On inquiring if the participants had ever received information regarding OA management from sources other than doctors, 42 (21\%) participants agreed that they acquired knowledge from the internet. If counseled properly, most participants (87.9\%) were willing to lose weight with a p-value of 0.01 (alpha $\leqslant 0.05$ ), illustrated in Figure 1 .

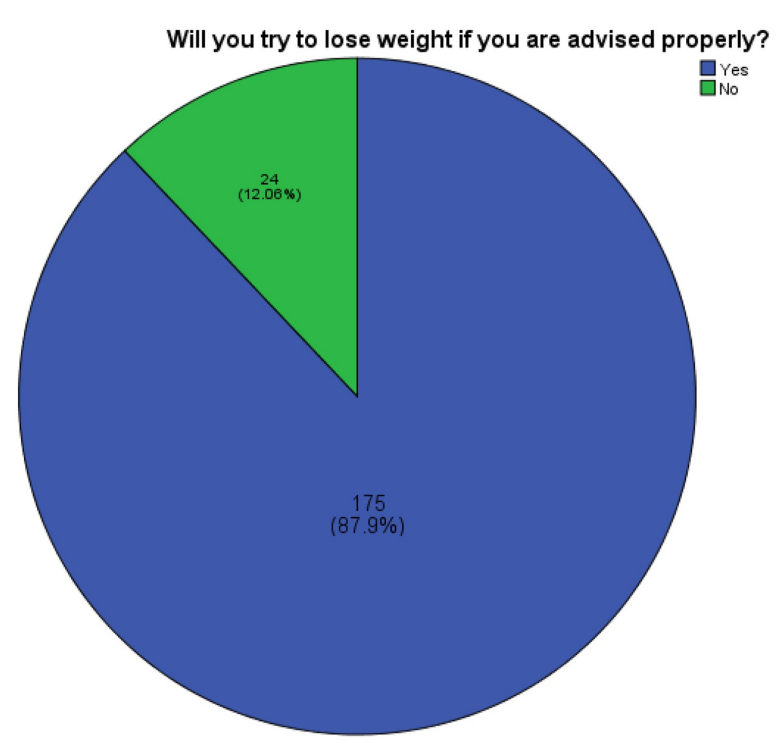


A Chi-square test was applied to see if there was a statistically significant difference between education and the patient's will to lose weight but the results showed a p-value of more than 0.05 for all categories of education. From this, we can conclude that education has no significant relation with a willingness to lose weight, as shown in Table 1.

\begin{tabular}{|c|c|c|c|}
\hline Education status & Willing to lose weight & Unwilling to lose weight & p-Value \\
\hline Uneducated & 42 & 8 & 0.32 \\
\hline High school & 76 & 11 & 0.82 \\
\hline Bachelor's degree & 32 & 3 & 0.49 \\
\hline Master's degree & 25 & 2 & 0.42 \\
\hline
\end{tabular}

TABLE 1: Comparison of the level of education with the willingness to lose weight.

\section{Discussion}

Lifestyle modification has been gaining increasing recognition as an important part of the management of OA [13]. Emphasis is being made regarding the importance of counseling on increased physical therapy and weight loss in patients with OA [13]. Reduction in body weight has proven to be beneficial for OA patients in several ways [14]. There are researches that support that body fat reduction may improve the prognosis of knee OA more than pharmacologic therapies [15]. NICE guidelines also propose that treatment of OA starts with a nonpharmacological approach which includes exercise [16]. The mechanism by which obesity aggravates OA is not well known [17]. An overweight patient who previously had a normal BMI is at a relatively higher risk of OA than patients who were persistently overweight [14-18].

Our study showed that less than half of the participants had received weight-loss counseling. According to a study, overweight and obese patients with OA were more likely to lose weight if advised adequately [17, 1920]. Clinicians have been facing several difficulties in counseling OA patients regarding weight loss [21]. These difficulties being: insufficient time during an appointment, lack of awareness of appropriate exercises, and uncertain billing procedures [21-22].

Some adults with OA have reported being unwilling to exercise due to their physical limitations. They feel that their activity is limited due to pain in their knees, increasing age, and other diseases if present. Therefore, interventions using cognitive behavioral therapy can lead to significant weight loss [23-24]. Physicians and other healthcare professionals should not underestimate the influence of their advice on the behavior of patients. Many physicians have been reported to consider OA less important than other lifethreatening conditions so less time and work is being put towards its management and research [25-26].

In our study, the majority of participants were willing to lose weight after they have received weight-loss counseling ( $p$-value $\leqslant 0.05$ ). On studying the relation between weight-loss counseling and the education level of participants, we concluded that education has no significant effect on the willingness to lose weight after counseling. From this, we can deduce that willingness to lose weight is mostly related to whether the counseling has been received or not, and not related to the education level of the participants.

Our study has been limited by the fact that all data on weight loss counseling are based on self-reports. Therefore, recall bias is possible. Another limitation is that the data were collected from a single tertiary care center on a limited number of participants so the study results cannot be generalized to a bigger population.

Further research is required to emphasize the importance of weight loss in the management of OA. Steps should be taken by health authorities to educate clinicians to incorporate weight-loss counseling in their practice. Moreover, health awareness schemes regarding the effect of weight loss on OA prognosis should also be made possible. 


\section{Conclusions}

As per our study, the number of OA patients who receive weight-loss counseling is low. Physicians need to counsel patients because as per our research, a significant number of OA patients were willing to lose weight if they have been counseled ( $\mathrm{p}$ value $\leqslant 0.05$ ). Our study also showed that willingness to lose weight is mostly related to whether the counseling has been received or not, and not related to the education level of the participants. Further studies are needed to understand the obstacles healthcare professionals are facing with weight-loss counseling and weight-loss counseling effects on the behavior of patients. Steps should be taken to encourage healthcare professionals to increase the counseling frequency regarding weight loss in OA patients.

\section{Additional Information \\ Disclosures}

Human subjects: Consent was obtained by all participants in this study. Army Cardiac Centre Ethical Review Board issued approval 21/20. It is certified that ethical committee of this centre have no objection for publication of article "Do patients with osteoarthritis get weight loss counselling?" written by Dr. Bismah Riaz. Animal subjects: All authors have confirmed that this study did not involve animal subjects or tissue. Conflicts of interest: In compliance with the ICMJE uniform disclosure form, all authors declare the following: Payment/services info: All authors have declared that no financial support was received from any organization for the submitted work. Financial relationships: All authors have declared that they have no financial relationships at present or within the previous three years with any organizations that might have an interest in the submitted work. Other relationships: All authors have declared that there are no other relationships or activities that could appear to have influenced the submitted work.

\section{References}

1. Goodman S: Osteoarthritis. Expert Guide to Rheumatology. Yee A, Paget S (ed): American College of Physicians, Philadelphia, PA; 2005. 269-283.

2. Woolf AD, Pfleger B: Burden of major musculoskeletal conditions. Bull World Health Organ. 2003, 81:646656.

3. Bliddal H, Leeds AR, Christensen R: Osteoarthritis, obesity and weight loss: evidence, hypotheses and horizons - a scoping review. Obes Rev. 2014, 15:578-586.

4. Hales CM, Carroll MD, Fryar CD, Ogden CL: Prevalence of obesity among adults and youth: United States, 2015-2016. NCHS Data Brief. 2017, 1-8.

5. Chooi YC, Ding C, Magkos F: The epidemiology of obesity. Metabolism. 2019, 92:6-10.

6. Kelly T, Yang W, Chen CS, et al.: Global burden of obesity in 2005 and projections to 2030 . Int J Obes. 2008, 32:1431-1437.

7. Christensen R, Bartels EM, Astrup A, et al.: Effect of weight reduction in obese patients diagnosed with knee osteoarthritis: a systematic review and meta-analysis. Ann Rheum Dis. 2007, 66:433-439.

8. Miller GD, Nicklas BJ, Davis C, et al.: Intensive weight loss program improves physical function in older obese adults with knee osteoarthritis. Obesity. 2006, 14:1219-1230. 10.1038/oby.2006.139

9. O'Brien KM, Wiggers J, Williams A, et al.: Telephone-based weight loss support for patients with knee osteoarthritis: a pragmatic randomised controlled trial. Osteoarthritis Cartilage. 2018, 26:485-494. 10.1016/j.joca.2018.01.003

10. McAlindon TE, Bannuru R, Sullivan MC, et al.: OARSI guidelines for the non-surgical management of knee osteoarthritis. Osteoarthritis Cartilage. 2014, 22:363-388. 10.1016/j.joca.2014.01.003

11. National Institute for Health and Clinical Excellence: Osteoarthritis. Care and management in adults. Clinical Guideline CG177 [Internet] . National Clinical Guideline Centre (UK). 2014,

12. Thomsen T, Esbensen BA, Hetland ML, et al.: Motivational counseling and text message reminders: for reduction of daily sitting time and promotion of everyday physical activity in people with rheumatoid arthritis. Rheum Dis Clin. 2019, 45:231-244.

13. Doherty M: Lifestyle changes in the management of osteoarthritis . Best Pract Res Clin Rheumatol. 2001, 15:559-568.

14. Markmann P, Toubro S, Astrup A: Sustained improvement in blood lipids, coagulation, and fibrinolysis after major weight loss in obese subjects. Eur J Clin Nutr. 1998, 52:329-333.

15. Toda Y, Toda T, Takemura S, Wada T, Morimoto T, Ogawa R: Change in body fat, but not body weight or metabolic correlates of obesity, is related to symptomatic relief of obese patients with knee osteoarthritis after a weight control program. J Rheumatol. 1998, 25:2181-2186.

16. National Institute for Health and Care Excellence. Osteoarthritis: care and management. NICE Clinical Guideline 177. (2014). Accessed: May 1, 2019: https://www.nice.org.uk/guidance/cg177.

17. Vincent HK, Heywood K, Connelly J, et al.: Obesity and weight loss in the treatment and prevention of osteoarthritis. PM R. 2012, 4:S59-S67.

18. Manninen P, Riihimaki H, Heliövaara M, Suomalainen O: Weight changes and the risk of knee osteoarthritis requiring arthroplasty. Ann Rheum Dis. 2004, 63:1434-1437. 10.1136/ard.2003.011833

19. Mehrotra C, Naimi TS, Serdula M, et al.: Arthritis, body mass index, and professional advice to lose weight: implications for clinical medicine and public health. Am J Prev Med. 2004, 27:16-21.

10.1016/j.amepre.2004.03.007

20. Fontaine KR, Haaz S, Bartlett SJ: Are overweight and obese adults with arthritis being advised to lose weight. J Clin Rheumatol. 2007, 13:12-15. 10.1097/01.rhu.0000256168.74277.15 


\section{Cureus}

21. Pinto BM, Goldstein MG, DePue JD, et al.: Acceptability and feasibility of physician-based activity counseling. The PAL project. Am J Prev Med. 1998, 15:95-102. 10.1016/S0749-3797(98)00043-9

22. Writing Group for the Activity Counseling Trial Research Group: Effects of physical activity counseling in primary care: the Activity Counseling Trial: a randomized controlled trial. JAMA. 2001, 286:677-687.

23. Hendry M, Williams NH, Markland D, et al.: Why should we exercise when our knees hurt? A qualitative study of primary care patients with osteoarthritis of the knee. Fam Pract. 2006, 23:558-567.

24. Wluka AE, Lombard CB, Cicuttini FM: Tackling obesity in knee osteoarthritis. Nat Rev Rheumatol. 2013, 9:225-235.

25. Colquitt JL, Picot J, Loveman E, Clegg AJ: Surgery for obesity. Cochr Datab Syst Rev. 2009,

26. Coar L: General practitioners' understanding and perceptions of osteoarthritis: an exploratory study . MPhil Thesis, Keele University, UK. 2004, 